\title{
Electrospun zein nanofibers incorporating cyclodextrins
}

\author{
Fatma Kayaci, Tamer Uyar* \\ UNAM-Institute of Materials Science E' Nanotechnology, Bilkent University, Ankara, 06800, Turkey
}

\section{A R T I C L E I N F O}

\section{Article history:}

Received 26 December 2011

Received in revised form 16 March 2012

Accepted 22 May 2012

Available online 30 May 2012

\section{Keywords:}

Cyclodextrin

Electrospinning

Zein

Nanofibers

\begin{abstract}
A B S T R A C T
Zein nanofibers containing cyclodextrins (zein/CD) were produced via electrospinning. Three types of $C D s(\alpha-C D, \beta-C D$ and $\gamma-C D)$ having $10 \%, 25 \%$ and $50 \%(w / w)$ were individually incorporated into zein nanofibers. SEM imaging elucidated that the morphologies of the electrospun zein/CD nanofibers depended on the CD type and weight percentage. The incorporation of CDs in zein improved the electrospinnability and bead-free nanofibers were obtained at lower zein concentrations. Zein/CD nanofibers having fiber diameters $\sim 100-400 \mathrm{~nm}$ were obtained depending on the zein concentrations, types and weight percentages of $C D$. XRD studies revealed that CDs were mostly distributed without forming crystalline aggregates for zein/CD nanofibers containing lower weight percentage of CDs. The surface analyses of zein/CD nanofibers by ATR-FTIR and XPS indicated that some of the CDs were present on the fiber surface. Thermal analyses showed that zein $\beta-C D$ nanofibers have shown higher glass transition temperatures and higher degradation temperature with increasing CD content.
\end{abstract}

(c) 2012 Elsevier Ltd. All rights reserved.

\section{Introduction}

Recently, electrospinning technique has gained a great interest since this technique is quite versatile for fabricating nanofibers/nanowebs from various synthetic or natural polymers, polymer blends, sol-gels, ceramics, etc. (Agarwal, Greiner, \& Wendorff, 2009; Bhardwaj \& Kundu, 2010; Ramakrishna et al., 2006; Teo \& Ramakrishna, 2009). Moreover, functional electrospun nanofibrous composite structures can also be produced by incorporating functional additives and/or nanoparticles in the fiber matrix or on the fiber surface (Andrew \& Clarke, 2008; Anitha, Brabu, Thiruvadigal, Gopalakrishnan, \& Natarajan, 2012; Dong, Wang, Sun, \& Hinestroza, 2008; He, Hu, Yao, Wang, \& Yu, 2009; Roso, Sundarrajan, Pliszka, Ramakrishna, \& Modesti, 2008; Zhang, Shao, et al., 2011). Unique properties of electrospun nanofibers/nanowebs including a relatively large surface area to volume ratio and pore sizes within the nanoscale and multi-functionality due to the presence of functional additives and nanoparticles make them favorable candidates in a variety of application areas such as membranes/nanofilters, wound dressing, tissue engineering, drug delivery, nanotextiles, nanocomposites, energy, environment, etc. (Agarwal et al., 2009; Bhardwaj \& Kundu, 2010; Chigome, Darko, \& Torto, 2011; Lu, Wang, \& Wei, 2009; Ramakrishna et al., 2006; Teo \& Ramakrishna, 2009; Thavasi, Singh, \& Ramakrishna, 2008; Xie, Li, \& Xia, 2008; Yoon, Hsiao, \& Chu, 2008).

\footnotetext{
* Corresponding author. Tel.: +90 3122903571; fax: +90 3122664365.

E-mail addresses: tamer@unam.bilkent.edu.tr, tameruyar@gmail.com (T. Uyar).
}

In recent years, biopolymers from renewable resources such as zein have gained attention for economical and environmental reasons (Paraman, \& Lamsal, 2011; Selling \& Woods, 2008; Selling, Woods, Sessa, \& Biswas, 2008). Zein, the major protein of corn and a by-product of the bioethanol industry, is a non-toxic, biocompatible, biodegradable polymer and this polymer can form films. Zein films and zein micro/nano particles can be used for encapsulation of essential oils, aromas and flavors, controlled release of active additives and as an active food packaging material, etc. (Alkan et al., 2011; Parris, Cooke, \& Hicks, 2005; Patel, Heussen, Hazekamp, Drost, \& Velikov, 2012; Sanchez-Garcia, Hilliou, \& Lagaron, 2010; Shi, Kokini, \& Huang, 2009; Zhong, Jin, Davidson, \&Zivanovic, 2009). In the recent years, electrospinning of zein nanofibers have received much attention as well (Jiang, Reddy, \& Yang, 2010; Jiang \& Yang, 2011; Jiang, Zhao, \& Zhu, 2007; Miyoshi, Toyohara, \& Minematsu, 2005; Selling et al., 2007, 2008; Torres-Giner, Gimenez, \& Lagaron, 2008; Yao, Li, \& Song, 2009). These studies are mostly related to the optimization of the electrospinning parameters of zein nanofibers (Miyoshi et al., 2005; Selling et al., 2007; Torres-Giner et al., 2008), crosslinking of zein nanofibers (Jiang et al., 2010; Jiang \& Yang, 2011; Selling et al., 2008) and blending of zein with some other type of biopolymers (Jiang et al., 2007; Yao et al., 2009a; Yao, Li, Song, $\mathrm{Li}, \& \mathrm{Pu}, 2007)$. In addition, $\beta$-carotene which is a bioactive antioxidant (Li, Lim, \& Kakuda, 2009) and (-)-epigallocatechin gallete that is a plant polyphenol (Fernandez, Torres-Giner, \& Lagaron, 2009) were incorporated into electrospun zein nanofiber matrix for the stabilization of these active additives.

Our particular interest is the functionalization of electrospun nanofibers with cyclodextrins (CDs). CDs are cyclic oligosaccharides having a toroid-shaped molecular structure. The most 

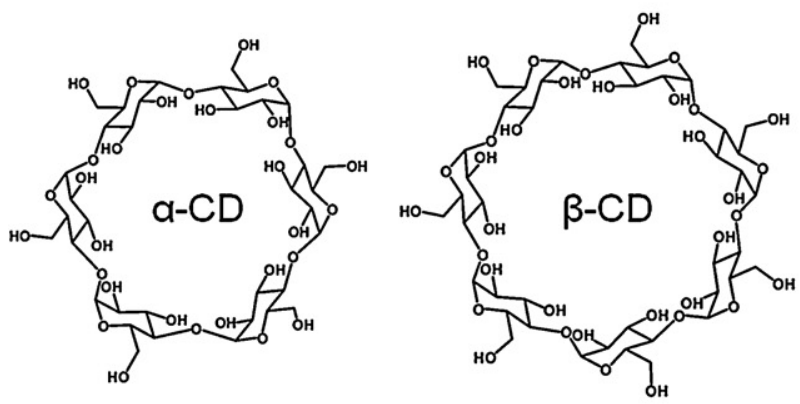

(a)
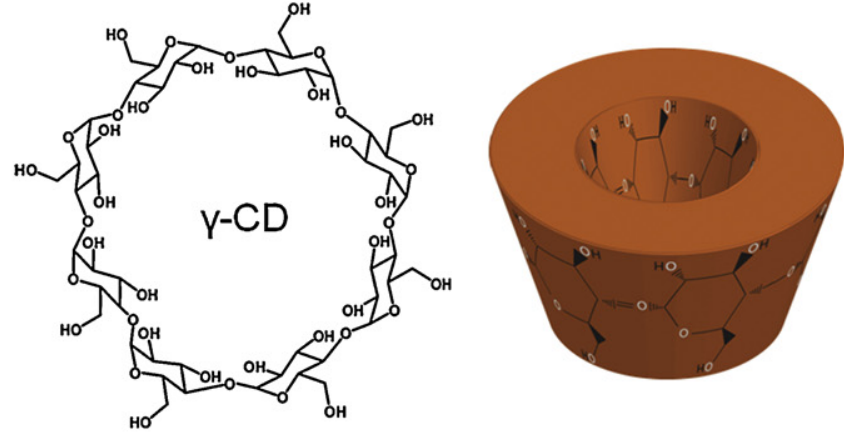

(b)

Fig. 1. (a) Chemical structures of $\alpha-C D, \beta-C D$ and $\gamma-C D$ and (b) schematic representation of CD

common CDs are named as $\alpha-C D, \beta-C D$ and $\gamma$-CD having 6,7 and 8 glucopyranose units, respectively (Fig. 1). Hydrophobic cavity of $\mathrm{CD}$ acts as a host for the various molecules, and $\mathrm{CD}$ can form non-covalent host-guest inclusion complexes. The physical and chemical properties of the guest molecules are tailored and become more stable when complexed with CDs (Del Valle, 2004; Hedges, 1998; Szejtli, 1998), therefore, CDs and their inclusion complexes are quite applicable in many fields including pharmaceuticals, functional foods, cosmetics and home/personal care and textiles (Del Valle, 2004; Hedges, 1998; Szejtli, 1998, 2003). Up to date, several studies have been carried out dealing with incorporation of CDs in electrospun nanofibers for different purposes such as crosslinking of fiber matrix (Li \& Hsieh, 2005), molecular filtration (Uyar, Havelund, Hacaloglu, Besenbacher, \& Kingshott, 2010; Uyar, Havelund, Nur, et al., 2010, 2009; Zhang, Chen, \& Diao, 2011) and CD was also used as a reducing and stabilizing agent for gold (Bai et al., 2008) and silver (Chae, Kim, Yang, \& Rhee, 2011) nanoparticles formation. In our recent studies, CDs and CD inclusion complexes (CD-ICs) of volatile fragrances were successfully incorporated into electrospun nanofibers, and these $\mathrm{CD}$ functionalized electrospun nanofibers were used as molecular filters (Uyar, Havelund, Hacaloglu, et al., 2010; Uyar, Havelund, Nur, et al., 2010, 2009), and CD-ICs have provided longer shelf-life and stabilization of volatile fragrances at higher temperature (Kayaci \& Uyar, 2012; Uyar, Hacaloglu, \& Besenbacher, 2009; Uyar, Hacaloglu, \& Besenbacher, 2011; Uyar, Nur, Hacaloglu, \& Besenbacher, 2009).

In this study, we report on the electrospinning of zein nanofibers incorporating CDs. Electrospun zein/CD nanofibers were obtained by using three types of CDs; $\alpha-C D, \beta-C D$ and $\gamma-C D$ and the weight loadings of these CDs were varied from $10 \%$ up to $50 \%(\mathrm{w} / \mathrm{w})$ with respect to zein. We found that the addition of $C D$ in the polymer solutions improve the electrospinnability of the zein nanofibers at lower polymer concentration. The morphological, structural, surface and thermal characteristics of the resulting electrospun zein/CD nanofibers were characterized by SEM, XRD, ATR-FTIR, XPS, DSC and TGA. This study mainly deals with the optimization of electrospinning of zein/CD nanofibers and their morphological, structural, surface and thermal characterizations.

\section{Experimental part}

\subsection{Materials}

Zein from maize (Sigma-Aldrich) and N,N-dimethylformamide (DMF, Pestanal, Riedel) were purchased. The alpha-, beta- and gamma-cyclodextrins ( $\alpha-C D, \beta-C D$ and $\gamma-C D$ ) were purchased from Wacker Chemie AG (Germany). All materials were used as-received without any purification.

\subsection{Preparation of the solutions}

First, 40\%, 50\% and 60\% (w/v) zein were dissolved in DMF and electrospinning of zein solutions without CDs was performed. For the electrospinning of zein/CD solutions, $10 \%, 25 \%$ and $50 \%(\mathrm{w} / \mathrm{w}$, with respect to zein) $C D s(\alpha-C D, \beta-C D$ and $\gamma-C D)$ were dissolved in DMF and then, $40 \%, 50 \%$ and $60 \%$ zein (w/v, with respect to solvent of DMF) were added to each CD solution separately and stirred for $1 \mathrm{~h}$ at room temperature. The compositions of the solutions were summarized in Table 1 . Homogeneous and clear solutions were obtained for all of the zein/ $\beta$-CD compositions. On the other hand, the zein solutions containing $25 \%(w / w) \alpha-C D$ was slightly turbid and also the solutions containing 50\% (w/w) $\alpha-C D$ and $\gamma-C D$ were highly turbid. The resulting zein and zein/CD solutions were electrospun.

\subsection{Electrospinning}

The solutions were placed in a $3 \mathrm{~mL}$ syringe fitted with a metallic needle having inner diameter of $0.8 \mathrm{~mm}$. The syringe was fixed horizontally on the syringe pump (Model: SP 101IZ, WPI). Several parameters were applied in order to optimize the electrospinning of the solutions and the optimal parameters were chosen as follows. Voltage of $15 \mathrm{kV}$ was applied to the metal needle tip by using high voltage power supply (AU Series, Matsusada Precision Inc.). The polymer solution was pumped with flow rate of $0.5 \mathrm{~mL} / \mathrm{h}$ during electrospinning and the tip-to-collector distance was set to $12 \mathrm{~cm}$. The grounded stationary cylindrical metal collector (height: $15 \mathrm{~cm}$, diameter: $9 \mathrm{~cm}$ ) covered with aluminum foil was used for the deposition of the electrospun nanofibers. The electrospinning process was carried out at $24^{\circ} \mathrm{C}$ and $30 \%$ relative humidity in an enclosed Plexiglas box.

\subsection{Measurements and characterization}

The viscosity of the solutions was measured by using Anton Paar Physica MCR 301 Rheometer equipped with cone/plate accessory using the spindle type $\mathrm{CP} 40-2$ at $22^{\circ} \mathrm{C}$ and a constant shear rate of $100 \mathrm{~s}^{-1}$. The conductivity measurement of the solutions was performed by using Multiparameter meter InoLab ${ }^{\circledR}$ Multi 720 (WTW) at room temperature.

The morphology and the diameter of the nanofibers were examined by using scanning electron microscope (SEM) (FEI-Quanta 200 FEG). The nanofibers were coated with $5 \mathrm{~nm} \mathrm{Au} / \mathrm{Pd}$ prior to SEM imaging. Around 100 fiber diameters were measured from the SEM images to determine the average fiber diameter (AFD) of the nanofibers. 
Table 1

Properties of zein and zein/CD solutions and the resulting zein and zein/CD nanofibers.

\begin{tabular}{|c|c|c|c|c|c|c|}
\hline Solutions & $\begin{array}{l}\% \text { zein } \\
(\mathrm{w} / \mathrm{v})^{\mathrm{a}}\end{array}$ & $\begin{array}{l}\text { Type of CD (\%) } \\
(w / w)^{b}\end{array}$ & $\begin{array}{l}\text { Viscosity } \\
\text { (Pa s) }\end{array}$ & $\begin{array}{l}\text { Conductivity } \\
(\mu \mathrm{S} / \mathrm{cm})\end{array}$ & Fiber morphology & $\begin{array}{l}\text { Average fiber diameter } \\
(\mathrm{AFD})(\mathrm{nm})\end{array}$ \\
\hline zein40 & 40 & - & 0.0332 & 435 & Nanofibers with many beads & - \\
\hline zein50 & 50 & - & 0.0859 & 344 & Nanofibers with few beads & $80 \pm 35$ \\
\hline zein60 & 60 & - & 0.206 & 264 & Bead-free nanofibers & $170 \pm 30$ \\
\hline zein $40 / \alpha-C D 10$ & 40 & $\alpha-\mathrm{CD}, 10$ & 0.0421 & 359 & Nanofibers with many beads & - \\
\hline zein40/ $\beta-C D 10$ & 40 & $\beta-C D, 10$ & 0.0428 & 357 & Nanofibers with many beads & - \\
\hline zein $40 / \gamma-C D 10$ & 40 & $\gamma-C D, 10$ & 0.0439 & 333 & Nanofibers with few beads & $60 \pm 10$ \\
\hline zein $40 / \alpha-C D 25$ & 40 & $\alpha-C D, 25$ & 0.0522 & 270 & Nanofibers with few beads & $60 \pm 20$ \\
\hline zein40/ß-CD25 & 40 & $\beta-C D, 25$ & 0.0562 & 283 & Nanofibers with few beads & $70 \pm 20$ \\
\hline zein $40 / \gamma-C D 25$ & 40 & $\gamma-C D, 25$ & 0.0732 & 267 & Nanofibers with few beads & $60 \pm 10$ \\
\hline zein $40 / \alpha-C D 50$ & 40 & $\alpha-C D, 50$ & 0.0849 & 96.8 & Nanofibers with beads and CD aggregates & - \\
\hline zein $40 / \beta-C D 50$ & 40 & $\beta-C D, 50$ & 0.0727 & 78.8 & Nanofibers with beads and CD aggregates & - \\
\hline zein $40 / \gamma$-CD50 & 40 & $\gamma-C D, 50$ & 0.101 & 115.6 & Nanofibers with beads and CD aggregates & - \\
\hline zein $50 / \alpha-C D 10$ & 50 & $\alpha-\mathrm{CD}, 10$ & 0.125 & 286 & Bead-free nanofibers & $90 \pm 20$ \\
\hline zein $50 / \beta-C D 10$ & 50 & $\beta-C D, 10$ & 0.171 & 278 & Bead-free nanofibers & $100 \pm 25$ \\
\hline zein $50 / \gamma-C D 10$ & 50 & $\gamma-\mathrm{CD}, 10$ & 0.212 & 268 & Bead-free nanofibers & $110 \pm 30$ \\
\hline zein $50 / \alpha-C D 25$ & 50 & $\alpha-\mathrm{CD}, 25$ & 0.212 & 138 & Nanofibers with CD aggregates & $185 \pm 45$ \\
\hline zein50/ß-CD25 & 50 & $\beta-C D, 25$ & 0.208 & 167 & Bead-free nanofibers & $150 \pm 30$ \\
\hline zein $50 / \gamma-C D 25$ & 50 & $\gamma-C D, 25$ & 0.239 & 161 & Bead-free nanofibers & $155 \pm 35$ \\
\hline zein $50 / \alpha-C D 50$ & 50 & $\alpha-\mathrm{CD}, 50$ & 0.39 & 74.3 & Nanofibers with CD aggregates & $240 \pm 85$ \\
\hline zein $50 / \beta-C D 50$ & 50 & $\beta-C D, 50$ & 0.381 & 97.8 & Nanofibers with $C D$ aggregates & $360 \pm 140$ \\
\hline zein $50 / \gamma$-CD50 & 50 & $\gamma-C D, 50$ & 0.354 & 126.5 & Nanofibers with CD aggregates & $265 \pm 110$ \\
\hline zein $60 / \alpha-C D 10$ & 60 & $\alpha-C D, 10$ & 0.329 & 211 & Bead-free nanofibers & $225 \pm 30$ \\
\hline zein60/ $\beta-C D 10$ & 60 & $\beta-C D, 10$ & 0.292 & 200 & Bead-free nanofibers & $185 \pm 40$ \\
\hline zein $60 / \gamma$-CD10 & 60 & $\gamma-C D, 10$ & 0.218 & 189.4 & Bead-free nanofibers & $170 \pm 40$ \\
\hline zein $60 / \alpha-C D 25$ & 60 & $\alpha-\mathrm{CD}, 25$ & 0.69 & 89.8 & Nanofibers with CD aggregates & $375 \pm 80$ \\
\hline zein60/ $\beta-C D 25$ & 60 & $\beta-C D, 25$ & 0.441 & 113 & Bead-free nanofibers & $410 \pm 130$ \\
\hline zein $60 / \gamma-C D 25$ & 60 & $\gamma-C D, 25$ & 0.664 & 109.6 & Bead-free nanofibers & $380 \pm 240$ \\
\hline zein $60 / \alpha-C D 50$ & 60 & $\alpha-\mathrm{CD}, 50$ & 1.56 & 41.6 & No fiber formation & - \\
\hline zein60/ $\beta$-CD50 & 60 & $\beta-C D, 50$ & 1.02 & 85.6 & No fiber formation & - \\
\hline zein $60 / \gamma-C D 50$ & 60 & $\gamma-C D, 50$ & 0.752 & 85.8 & No fiber formation & - \\
\hline
\end{tabular}

a With respect to solvent (DMF).

b With respect to polymer (zein).

X-ray diffraction (XRD) data of the nanofibers were collected by using PANalytical X'Pert Powder diffractometer with $\mathrm{Cu}$ K $\alpha$ radiation in a range $2 \theta=5-30^{\circ}$.

Surface characterizations of the nanofibers were performed by attenuated total reflectance Fourier transform infrared spectroscopy (ATR-FTIR) (Bruker, VERTEX 70) and K-Alphamonochromated high-performance X-ray photoelectron spectrometer (XPS) (Thermo Scientific). The ATR-FTIR spectra were recorded from 700 to $4000 \mathrm{~cm}^{-1}$ with a resolution of $4 \mathrm{~cm}^{-1}$ by taking 64 scans for each sample, and these spectra were obtained with FTIR spectrometer equipped with a liquid nitrogen cooled mercury cadmium telluride (MCT) detector by using ATR set up containing a germanium crystal. XPS was used by means of a flood gun charge neutralizer system equipped with a monochromated Al K$\alpha \mathrm{X}$-ray source $(h v=1486.6 \mathrm{eV})$. Wide energy survey scans (WESS) were obtained over the $0-1360 \mathrm{eV}$ binding energy (BE) range at a detector pass energy of $150 \mathrm{eV}$ in order to determine the surface elemental composition of the nanofibers. The high resolution spectra were recorded for $\mathrm{C} 1 \mathrm{~s}$ region at pass energy of $50 \mathrm{eV}$.

The thermal properties of the nanofibers were investigated by using differential scanning calorimetry (DSC) (TA Q2000) and thermal gravimetric analyzer (TGA) (TA Q500). DSC analyses were carried out with about $5 \mathrm{mg}$ of samples under the $\mathrm{N}_{2}$ as a purge gas. Initially, the samples were equilibrated at $25^{\circ} \mathrm{C}$ then they were heated to $200^{\circ} \mathrm{C}$ at $10^{\circ} \mathrm{C} / \mathrm{min}$. TGA was performed from room temperature to $500^{\circ} \mathrm{C}$ at a heating rate of $20^{\circ} \mathrm{C} / \mathrm{min}$ under the nitrogen atmosphere.

\section{Results and discussion}

\subsection{Electrospinning of zein nanofibers}

In the literature, the electrospinning of zein nanofibers was mostly carried out by using ethanol/water mixture solvent system which resulted in ribbon-like fiber morphology due to the rapid skin formation and collapse of the fiber core because of the very fast evaporation of the solvent (Miyoshi et al., 2005; Selling et al., 2007; Torres-Giner et al., 2008). However, round-shaped zein nanofibers can be obtained by using solvent systems having high boiling points such as DMF (Jiang et al., 2007). In our study, the electrospinning of zein nanofibers was carried out by using DMF as a solvent system. The reason of choosing DMF is because thinner and more uniform zein fibers can be obtained (Jiang et al., 2007) when compared to ethanol/water system (Miyoshi et al., 2005; Selling et al., 2007;
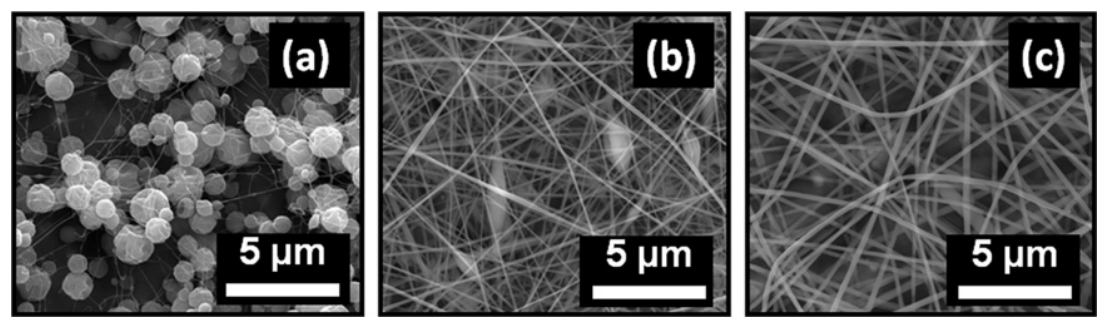

Fig. 2. Representative SEM images of electrospun zein nanofibers obtained from zein solutions in DMF at a concentration of (a) $40 \%$, (b) $50 \%$ and (c) $60 \%$ (w/v). 
Torres-Giner et al., 2008), and other more important reason is that DMF is a very good solvent for CDs, and therefore we were able to prepare zein/CD homogeneous solutions in most cases.

The characteristics (composition, viscosity and conductivity) of the zein and zein/CD solutions and the morphologies of the electrospun nanofibers and their average fiber diameter (AFD) are summarized in Table 1. Zein solutions having different concentrations were electrospun in order to find the optimal polymer concentration for obtaining bead-free uniform nanofibers. The representative SEM images of zein nanofibers electrospun from $40 \%$, $50 \%$ and $60 \%(w / v)$ zein solutions in DMF are depicted in Fig. 2. At lower zein concentration $(40 \%, w / v)$, micron size irregular spherical beaded structures were obtained due to the low viscosity of the polymer solution. As the concentration of zein solution was increased to $50 \%(\mathrm{w} / \mathrm{v})$, the number of beads was decreased significantly and the shape of beads became more elongated and nanofibers having AFD of $80 \pm 35 \mathrm{~nm}$ were obtained. Uniform and bead-free zein nanofibers having AFD of $170 \pm 30 \mathrm{~nm}$ were obtained when $60 \%(\mathrm{w} / \mathrm{v})$ zein solution was electrospun indicating that $60 \%$ $(\mathrm{w} / \mathrm{v})$ is the optimal zein concentration for producing uniform zein nanofibers at the applied electrospinning conditions. Our results correlate with the literature findings where the bead-free uniform zein nanofibers were produced above $50 \%(\mathrm{w} / \mathrm{v})$ zein concentration when DMF was used as a solvent system (Jiang et al., 2007). This behavior is very typical for the electrospinning of polymeric solutions where the transition from beaded structure to bead-free nanofibers is observed by increasing the polymer concentration. Higher polymer concentration resulted in higher solution viscosity due to the presence of more polymer chain entanglements and therefore the beaded structures are eliminated since the electrified polymer jet can be stretched fully yielding bead-free nanofibers (Ramakrishna, Fujihara, Teo, Lim, \& Ma, 2005; Uyar \& Besenbacher, 2008).

\subsection{Electrospinning of zein/CD nanofibers}

The zein/CD solutions were clear and homogeneous except for the solutions containing higher weight percentage of $\alpha-C D$ and $\gamma$ $C D$. The zein $/ \beta-C D$ solutions were clear in all compositions whereas the zein/CD solutions containing 50\% (w/w) $\alpha$-CD and $\gamma$-CD were highly turbid, and zein/CD solution containing $25 \%(w / w) \alpha-C D$ was slightly turbid. The turbidity was observed possibly because of the precipitation of the $\alpha-C D$ and $\gamma-C D$ at higher \% loading, and it is anticipated that the electrospinning of these zein/CD solutions would contain $C D$ aggregates in the fiber matrix. In the case of clear zein/CD solutions, the homogeneous distribution of the CDs in the fiber matrix is expected for the electrospun zein/CD nanofibers containing lower amount of CDs. The SEM imaging of the electrospun zein/CD nanofibers gave some insightful information for the presence of $C D$ aggregates in the fiber matrix.

The representative SEM images of the electrospun zein/CD nanofibers are depicted in Fig. 3. It was observed that the addition of CDs to zein solutions improved the electrospinnability, and less beaded structures and/or bead-free nanofibers were obtained at lower zein concentrations when compared to zein solutions without CDs.

The electrospinning of $40 \%(\mathrm{w} / \mathrm{w})$ zein solutions containing CDs resulted in nanofibers having much less beaded structure when compared to $40 \%$ (w/w) pristine zein solution. Fig. 3a shows the SEM images of electrospun zein/CD nanofibers obtained from $40 \%(\mathrm{w} / \mathrm{v})$ zein solution containing $10 \%, 25 \%$ and $50 \%(\mathrm{w} / \mathrm{w}$, with respect to zein) $\mathrm{CDs}(\alpha-\mathrm{CD}, \beta-\mathrm{CD}$ and $\gamma-\mathrm{CD})$. The electrospinning of $40 \%(\mathrm{w} / \mathrm{w})$ zein solutions containing $10 \%(\mathrm{w} / \mathrm{w})$ CDs resulted in reduction of beads to some extent (Fig. 3a1-a3). In the case of zein $40 / \gamma$-CD10 sample, the elimination of beads is much more pronounced which is possibly because of the higher solution viscosity compared to zein $40 / \alpha-C D 10$ and zein $40 / \beta-C D 10$ solutions. Furthermore, it was clearly observed that the addition of $25 \%$ $(\mathrm{w} / \mathrm{w})$ CDs to the $40 \%(\mathrm{w} / \mathrm{v})$ zein solutions improved the electrospinnability of the zein/CD solutions, and yielded nanofibers with much less beads having more elongated structures (Fig. 3a4-a6). This is possibly because of the higher solution viscosity of zein/CD systems where the beaded structures are mostly eliminated due to the more stretching of electrified solution jet. However, even the addition of $50 \%(w / w)$ CDs resulted in more viscous solutions, the electrospinning of these zein/CD solutions yielded nanofibers having irregular structures (Fig. 3a7-a9) suggesting that uniform zein/CD nanofibers cannot be produced when the high weight percentage of CDs was used. The irregular structures consisting of not only beads but also $\mathrm{CD}$ aggregates were much more prominent in zein $40 / \alpha$-CD50 and zein $40 / \gamma$-CD50 nanofibers when compared to zein $40 / \beta-C D 50$, since the zein $40 / \alpha-C D 50$ and zein $40 / \gamma-C D 50$ solutions were highly turbid prior to electrospinning indicating that $\mathrm{CD}$ aggregates were already present in the solution, and these $\mathrm{CD}$ aggregates possibly could not be stretched out along the fiber matrix during the electrospinning process. In the case of zein $40 / \beta$ CD50, the beads were less in number since the zein $40 / \beta-C D 50$ solution was clear, and some $\mathrm{CD}$ aggregates were possibly formed during the electrospinning process when the solvent evaporation took place.

The electrospinning of $50 \%(\mathrm{w} / \mathrm{v})$ zein solution yielded nanofibers with few beads as mentioned above (Fig. 2b), however, bead-free nanofibers were obtained from $50 \%(\mathrm{w} / \mathrm{v})$ zein solution with the addition of $10 \%$ and $25 \%(w / w)$ CDs $(\alpha-C D, \beta-$ $\mathrm{CD}$ and $\gamma$-CD) except for zein50/ $\alpha$-CD25 system (Fig. $3 b$ ). In the case of zein $50 / \alpha-C D 25$ nanofibers, some irregular structures were observed which is because of the presence of $\alpha$-CD aggregates as discussed later in the XRD section. Similar to $40 \%(\mathrm{w} / \mathrm{v})$ zein system, the addition of $50 \%(\mathrm{w} / \mathrm{w})$ CDs in $50 \%(\mathrm{w} / \mathrm{v})$ zein solution yielded nanofibers having irregular structures due to the aggregation of $\mathrm{CD}$ crystals as confirmed by XRD results. It was clear that the addition of CDs in certain ratios (10\% and $25 \%, \mathrm{w} / \mathrm{w})$ to the $50 \%(\mathrm{w} / \mathrm{v})$ zein solutions assisted to eliminate the bead formation and provided bead-free zein/CD nanofibers without increasing polymer concentration. We observed similar effect on the morphology of the electrospun PS (Uyar, Havelund, Hacaloglu, et al., 2009), PMMA (Uyar, Balan, Toppare, \& Besenbacher, 2009) and PEO (Uyar \& Besenbacher, 2009) nanofibers containing CDs in our recent studies.

The electrospinning of $60 \%$ zein $(\mathrm{w} / \mathrm{v})$ solutions containing $10 \%$ and $25 \%(\mathrm{w} / \mathrm{w}) \mathrm{CDs}$ resulted in bead-free nanofiber morphology except for zein60/ $\alpha$-CD25 system (Fig. 3c). The zein $60 / \alpha-C D 25$ nanofibers have some bead-like structures similar to zein $50 / \alpha-C D 25$ system which is possibly due to $C D$ aggregates. Furthermore, $60 \%$ zein $(\mathrm{w} / \mathrm{v})$ solution containing $50 \%(\mathrm{w} / \mathrm{w})$ CDs could not be electrospun due to the very high viscosity of the solutions.

In brief, the addition of CDs to zein solutions significantly affected the electrospinning, and bead-free nanofibers were obtained from lower zein concentrations for zein/CD systems when compared to pure zein solution. This is mostly due to the higher viscosity of the zein/CD solutions, and higher solution viscosity resulted in more uniform fibers when electrospun (Ramakrishna et al., 2005; Uyar \& Besenbacher, 2008). In addition, the morphologies of the zein/CD nanofibers containing different kind of CDs $(\alpha-C D, \beta-C D$ and $\gamma-C D)$ have shown slight variations among each other because of the differences in viscosity and conductivity of these solutions. It was observed in Table 1 that the AFD increases as the content of the CDs increases since the presence of CDs causes a viscosity increase of the solutions while it reduces the conductivity of the solutions. Therefore, zein/CD solutions having higher viscosity and lower conductivity values yielded thicker fibers due to the 

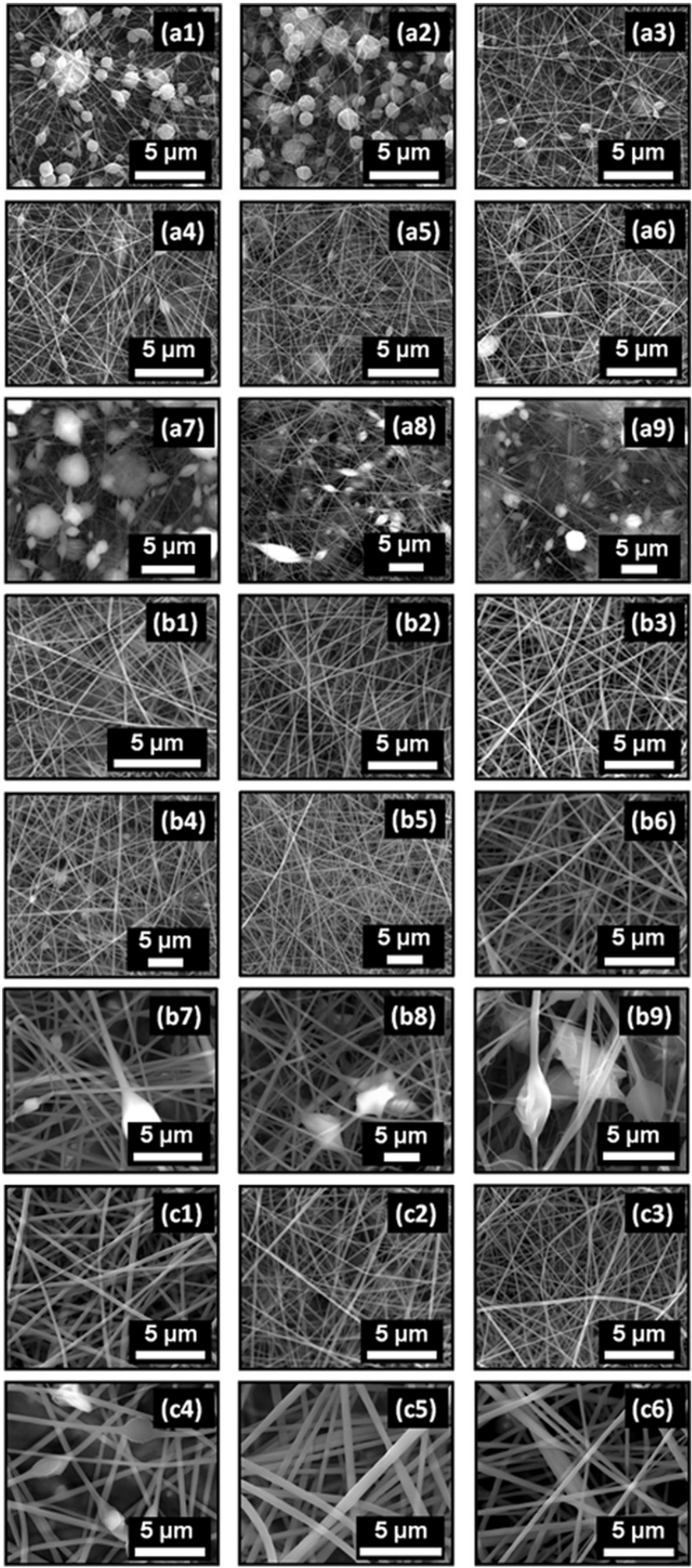

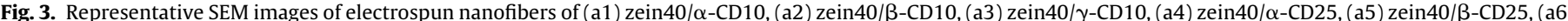

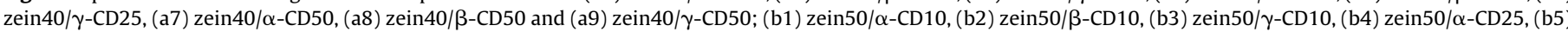

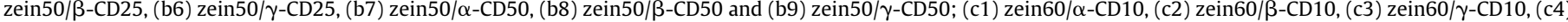
zein60/ $\alpha-C D 25$, (c5) zein60/ $\beta-C D 25$ and (c6) zein60/ $\gamma$-CD25. 

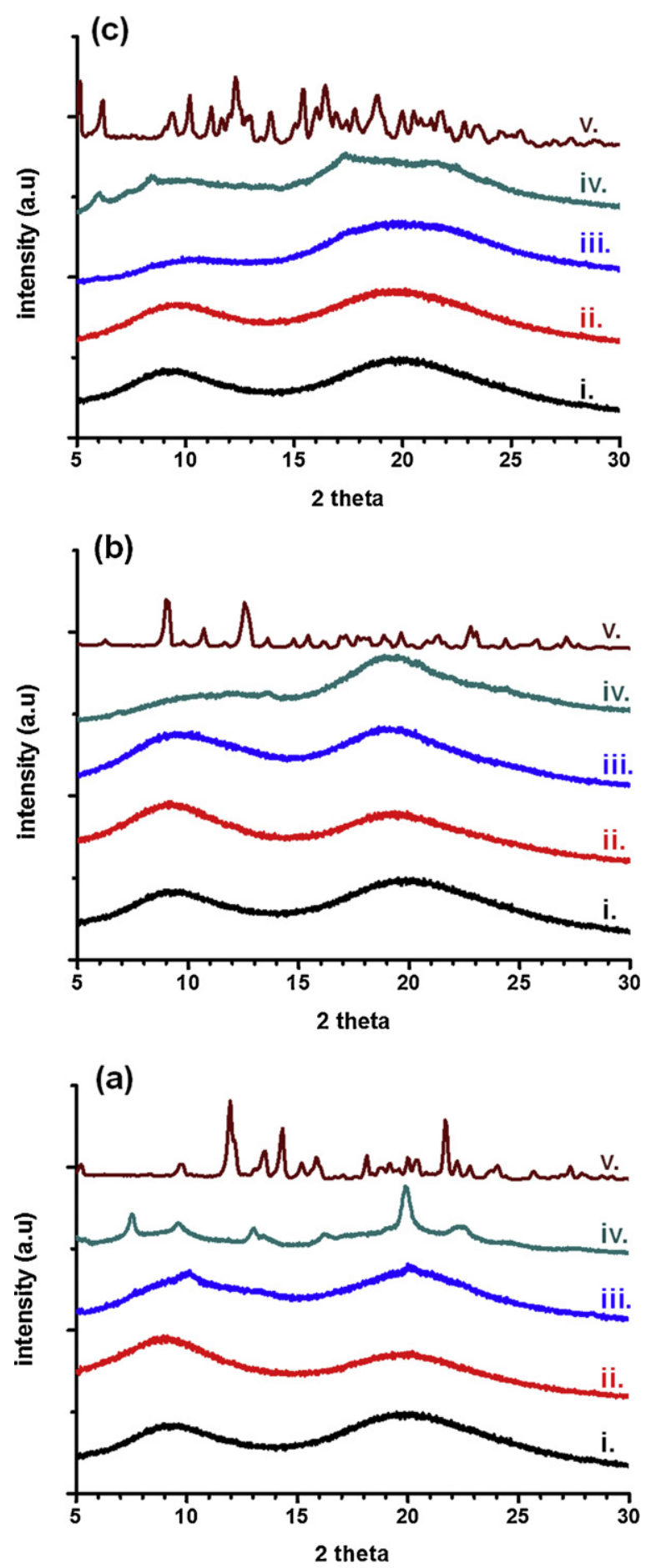

Fig. 4. XRD patterns of (a) (i) zein 50 , (ii) zein $50 / \alpha-C D 10$, (iii) zein $50 / \alpha-C D 25$, (iv) zein $50 / \alpha-C D 50$ and (v) $\alpha-C D$; (b) (i) zein50, (ii) zein $50 / \beta-C D 10$, (iii) zein $50 / \beta-C D 25$, (iv) zein50/ $\beta$-CD50 and (v) $\beta$-CD; (c) (i) zein50, (ii) zein50/ $\gamma$-CD10, (iii) zein $50 / \gamma$ CD25, (iv) zein $50 / \gamma$-CD50 and (v) $\gamma$-CD

less stretching of the electrified jet (Ramakrishna et al., 2005; Uyar \& Besenbacher, 2008).

\subsection{Structural characterization of zein/CD nanofibers}

The XRD patterns of electrospun zein nanofibers and zein/CD nanofibers are shown in Fig. 4 and the XRD patterns of asreceived $C D$ s were also shown for comparison. Zein nanofibers have shown two broad peaks having maxima at $2 \theta=8.99^{\circ}(9.8 \AA)$ and at
$2 \theta=19.38^{\circ}(4.58 \AA)$. It is reported that the larger $d$-spacing around $10 \AA$ is associated with the mean distance of approach of neighboring helices (the spacing of the inter-helix packing of zein chains) whereas the shorter $d$-spacing at around $4.5 \AA$ is related to the average backbone distance within $\alpha$-helix structure of zein (Yao, Li, Song, Li, \& Pu, 2009).

CDs $(\alpha-C D, \beta-C D$ and $\gamma-C D)$ are crystalline materials having distinct diffraction patterns at $2 \theta=5-30^{\circ}$ (Fig. 4). CDs generally have two types of crystal structures; in 'cage-type' the cavity of each $\mathrm{CD}$ molecule is blocked by the adjacent $\mathrm{CD}$ molecules whereas the $C D$ molecules are aligned and stacked on top of each other in the 'channel-type' structure. The XRD of as-received CDs have shown diffraction patterns for 'cage-type' crystalline structures as reported in the literature (Harata, 1998; Rusa et al., 2002; Saenger et al., 1998).

Some structural changes were observed for the zein/CD nanofibers depending on the weight percentages and types of CDs. The XRD of zein $50 / \alpha-C D 10$ nanofibers have shown two broad halo diffraction patterns centered at $2 \theta=8.94^{\circ}(9.9 \AA)$ and at $2 \theta=20.18^{\circ}$ (4.4 $\AA$ ) which is very similar to the zein nanofibers. The diffraction peaks for the $\alpha-C D$ crystals were absent in this sample indicating that $\alpha-C D$ molecules were distributed in the zein fiber matrix without forming any phase separated crystal aggregates. For zein $50 / \alpha-C D 25$ and zein $50 / \alpha-C D 50$ nanofibers, the decrease of the peak at $2 \theta=8.99^{\circ}$ suggested that the spacing of the inter-helix packing of zein chains was disturbed and the zein molecular aggregates were somehow destroyed with the presence of $\alpha-C D$ at higher weight percentages. Moreover, slightly intense diffraction peaks were observed for zein $50 / \alpha-C D 25$ nanofibers suggesting that some aggregation of $\alpha-C D$ crystals was present in this sample. The $\alpha-C D$ crystalline peaks were much more pronounced for the zein $50 / \alpha$ CD50 sample. This finding correlates with the SEM images where the bead-like structures for zein $50 / \alpha-C D 25$ and irregular structures for zein $50 / \alpha-C D 50$ were observed for these samples due to the presence of some $\alpha$-CD aggregates. The XRD patterns correspond to channel-type packing of $\alpha-C D$ since the salient diffraction peak $2 \theta \cong 20^{\circ}$ is characteristic for the $\alpha-C D$ channel-type (Harata, 1998; Rusa et al., 2002; Saenger et al., 1998). In general, the 'channeltype' packing of $C D$ is associated with the inclusion complex state. For instance, Tonelli et al. reported that protein based polymer such as Bombyx mori silk fibroin can form an inclusion complex with $\gamma$-CD (Cristian, Bridges, Ha, \& Tonelli, 2005). However, here we did not anticipate the inclusion complexation of zein with $\alpha$ $\mathrm{CD}$ due to the small size cavity of $\alpha-C D$. As mentioned in the experimental part, the zein $50 / \alpha-C D 25$ and zein $50 / \alpha-C D 50$ solutions were turbid and it is most likely that $\alpha-C D$ precipitated as 'channel-type' crystals in the zein/DMF solution system. We have also observed similar situations for electrospun PS containing $\alpha$ CD where the $\alpha$-CD precipitated as 'channel-type' crystals without forming inclusion complexation (Uyar, Havelund, Hacaloglu, et al., 2009). Additionally, the XRD of zein $50 / \beta-C D 50$ and zein $50 / \gamma$-CD50 have also shown some diffraction peaks due to the presence of some $\mathrm{CD}$ crystalline aggregates but these diffractions did not correspond to channel-type packing suggesting that CDs were not in the complex state with zein chains in zein50/CD50 nanofibers. In XRD, the typical channel-type $\beta-C D$ has two major peaks at $2 \theta \cong 11.5^{\circ}$ and $18^{\circ}$ (Harada, Okada, Li, \& Kamachi, 1995), and the characteristic diffraction for channel-type $\gamma$-CD has one major peak at $2 \theta \cong 7.5^{\circ}$ with minor reflections at $2 \theta \cong 14^{\circ}, 15^{\circ}, 16^{\circ}, 16.8^{\circ}$ and $22^{\circ}$ (Uyar, Hunt, Gracz, \& Tonelli, 2006). However, for zein50/ $\beta$-CD50 and zein50/ $\gamma$-CD50 nanofibers, the diffraction peaks were different than the channel-type packing as discussed below.

In XRD, it was observed that the diffraction patterns of zein $50 / \beta$ CD10 and zein50/ $\beta$-CD25 nanofibers were very similar to that of pure zein nanofibers (Fig. $4 \mathrm{~b}$ ). In the case of zein $50 / \beta-C D 50$ nanofibers, the intensity of first peak at around $2 \theta=9.0^{\circ}$ was 
lowered significantly indicating that the inter-helix packing of zein molecular aggregates were substantially disturbed. In addition, very weak diffraction peaks at around $2 \theta=6.9^{\circ}, 13.6^{\circ}$ and $24.4^{\circ}$ were observed for this sample possibly because of the presence of some $\beta$-CD aggregates in the fiber matrix. However, these peaks did not correspond to either cage-type packing or channel-type packing indicating that the regular packing of $\beta-C D$ was disturbed by the zein chains. For zein $50 / \beta-C D 10$ and zein $50 / \beta-C D 25$ nanofibers, no crystalline peaks were observed suggesting that $\beta-C D$ molecules were distributed in the fiber matrix without forming any crystal aggregates.

Moreover the incorporation of $\gamma$-CD into zein fiber matrix has a very similar structural effect as seen for zein $/ \alpha-C D$ and zein $/ \beta-C D$. The XRD pattern of zein50/ $\gamma$-CD10 nanofibers was similar to pure zein nanofibers showing two distinct broad halo at around $2 \theta=9^{\circ}$ and $2 \theta=20^{\circ}$ (Fig. 4c). The incorporation of $25 \%$ and $50 \%(w / w) \gamma-$ $\mathrm{CD}$ to fiber matrix resulted in disruption of inter-helix packing of zein chains as deduced from the XRD patterns of zein $50 / \gamma$-CD25 and zein $50 / \gamma$-CD50 since the peak at around $2 \theta=9^{\circ}$ was considerably weakened. In addition, certain diffraction peaks at around $2 \theta=6^{\circ}, 8.4^{\circ}$ and $17.4^{\circ}$ were observed for zein $50 / \gamma$-CD50 sample suggesting that some crystalline $\gamma$-CD aggregates were present in this sample as observed in the SEM image of this sample. Yet, these peaks somewhat different than the cage-type packing or channeltype packing suggesting that $\gamma$-CD packing was disturbed by the zein chains which was similarly observed for the zein $50 / \beta-C D 50$.

In brief, it was observed that the shorter $d$-spacing ca $4.5 \AA$ correlated to the average backbone distance in $\alpha$-helix structure of zein did not change with the addition of CDs, while the intensity of the larger $d$-spacing around $9 \AA$ associated with the mean distance of approach of neighboring helices decreased significantly as the content of CD increased from $10 \%$ to $50 \%(\mathrm{w} / \mathrm{w}$ ) in zein/CD nanofibers. This result implied the structural changes depending on the sidechain packing were observed for zein with the addition of CDs. Moreover, XRD data suggested that CDs were mostly distributed in the zein fiber matrix without forming crystalline aggregates at lower weight percentages ( $10 \%$ of $\alpha-C D$, and $10 \%$ and $25 \%$ of $\beta$ CD and $\gamma-C D$ ), but, incorporation of $25 \% \alpha-C D$ and $50 \%$ of all three types of CDs yielded some crystalline $\mathrm{CD}$ aggregates in the zein fiber matrix.

\subsection{Surface characterization of zein/CD nanofibers}

The surface analyses of zein/CD nanofibers were performed by using surface sensitive techniques, ATR-FTIR and XPS in order to corroborate the presence of $\mathrm{CDs}$ on the surface of the zein nanofibers. The ATR-FTIR spectra of the electrospun zein nanofibers and zein/CD nanofibers are shown in Fig. 5a. Zein protein backbone has two characteristic vibrational bands; amide I and amide II. The characteristic absorption band of amide I corresponds to the $\mathrm{C}=\mathrm{O}$ stretching, while that of amide II corresponds $\mathrm{N}-\mathrm{H}$ bending and $\mathrm{C}-\mathrm{N}$ stretching (Fernandez et al., 2009; Yao et al., 2009b). The characteristic absorption bands at 1653 and $1540 \mathrm{~cm}^{-1}$ indicated the presence of amide I and amide II, respectively for pure zein nanofibers (Fig. 5a1-a3).

The characteristic peak of coupled $\mathrm{C}-\mathrm{C} / \mathrm{C}-\mathrm{O}$ stretching vibrations and the antisymmetric stretching vibration of the $\mathrm{C}-\mathrm{O}-\mathrm{C}$ glycosidic bridge of $C D$ were observed for zein/CD nanofibers at 1028,1080 and $1150 \mathrm{~cm}^{-1}$, respectively (Uyar, Balan, et al., 2009). It was also clear that the intensity of CD related peaks was increased as the $C D$ content increased from $10 \%$ to $50 \%(w / w)$ in the zein/CD nanofibers. The ATR-FTIR data confirmed the successful incorporation of CDs in the zein nanofibers and some CDs were present on the surface of the zein/CD nanofibers.

In ATR-FTIR study, it was observed that the amide I and amide II peaks were slightly shifted to lower wavenumber for zein/CD
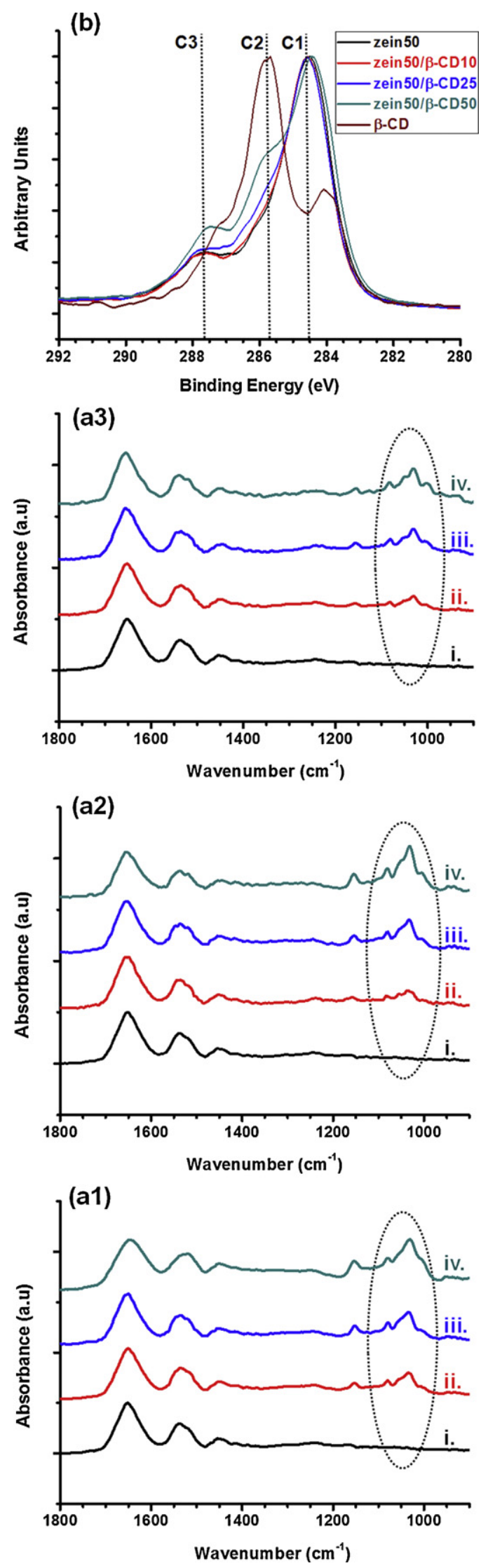

Fig. 5. ATR-FTIR spectra of electrospun nanofibers of (a1) (i) zein50, (ii) zein50/ $\alpha$ CD10, (iii) zein $50 / \alpha-C D 25$ and (iv) zein50/ $\alpha-C D 50$; (a2) (i) zein 50 , (ii) zein $50 / \beta-$ CD10, (iii) zein50/ $\beta-C D 25$ and (iv) zein50/ $\beta$-CD50; (a3) (i) zein50, (ii) zein $50 / \gamma$ CD10, (iii) zein50/ $\gamma$-CD25 and (iv) zein50/ $\gamma$-CD50 and (b) overlay of XPS C1s spectra of the zein and zein $/ \beta-C D$ nanofibers and pure $\beta-C D$ powder. 

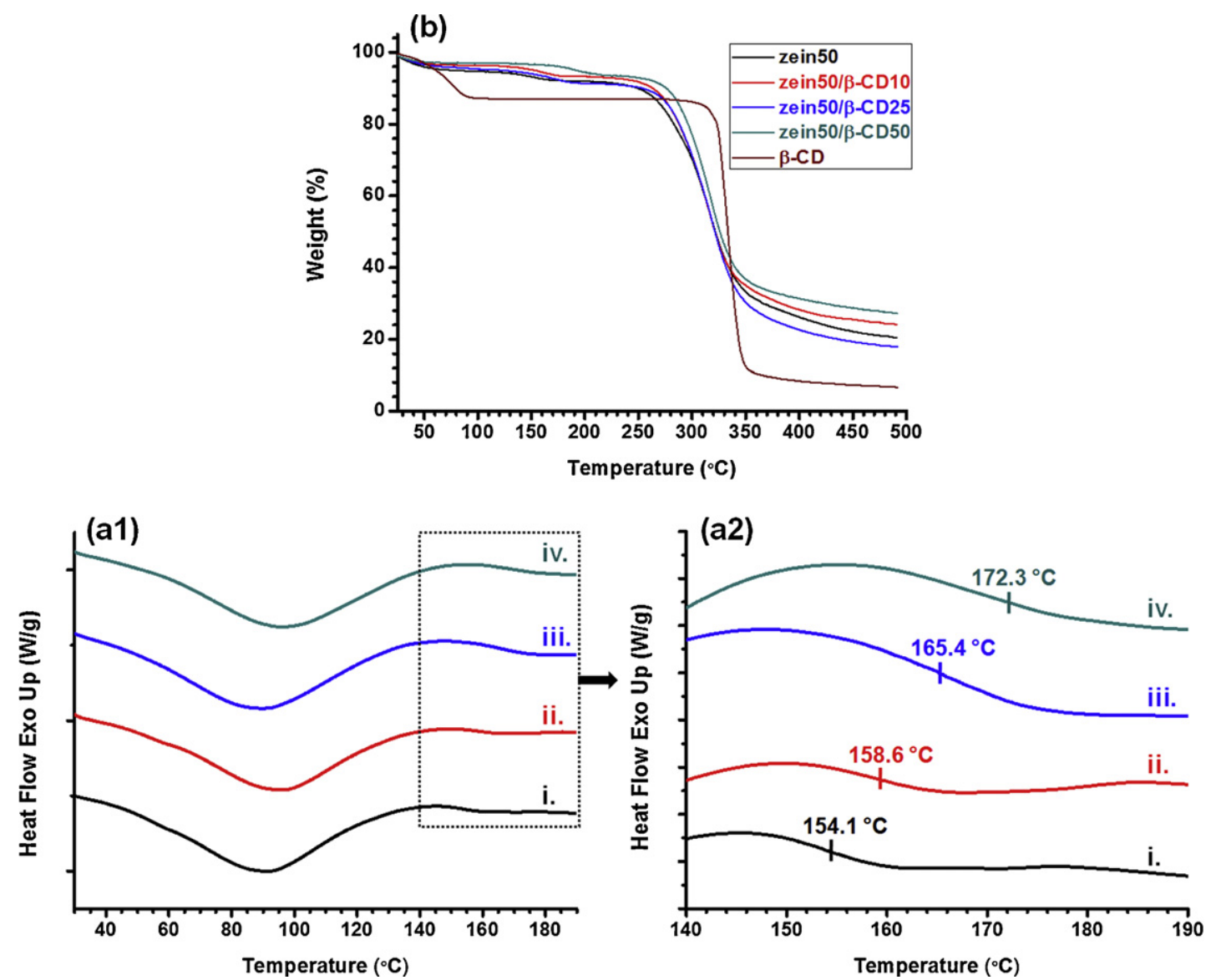

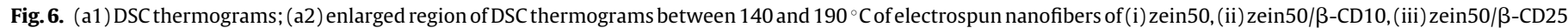
and (iv) zein50/ $\beta$-CD50 and (b) TGA thermograms of zein50 and zein50/ $\beta$-CD nanofibers and pure $\beta$-CD powder.

nanofibers when compared to pure zein nanofibers. For instance, the amide I peak was observed at 1651,1650 and $1648 \mathrm{~cm}^{-1}$ for zein $50 / \alpha-C D 10$, zein $50 / \alpha-C D 25$ and zein $50 / \alpha-C D 50$, respectively. Similarly, the amide II peak was shifted to lower wavenumber as the weight percentage of the $\alpha$-CD was increased from 10\% to $50 \%$. That is, absorption peak of amide II was observed at 1536, 1535 and $1520 \mathrm{~cm}^{-1}$ for zein $50 / \alpha-C D 10$, zein $50 / \alpha-C D 25$ and zein $50 / \alpha-$ CD50, respectively. The peak shift of amide I and amide II to lower wavenumbers for zein/CD nanofibers suggested the presence of interaction between zein and $\alpha-\mathrm{CD}$, and the interaction became more pronounced for nanofiber samples having higher loading of $\alpha-C D$. In the case of zein $/ \beta-C D$ and zein $/ \gamma-C D$ nanofiber samples, the shift in the amide I was not significant but the amide II peak was shifted to around $1535 \mathrm{~cm}^{-1}$ suggesting the presence of interaction between $\mathrm{CD}$ molecules and zein chains for these samples as well. But, the peak shift for amide I and amide II was much more significant in the case of zein $/ \alpha-C D$ nanofibers compared to zein $/ \beta-C D$ and zein $/ \gamma-C D$ nanofibers possible because $\alpha-C D$ has smaller size which can interact more with the zein chains.

As observed in the SEM imaging, the uniform nanofibers were obtained in the case of $\beta-C D$, therefore, more detailed surface analyses and thermal characterizations were carried out for zein $/ \beta-C D$ nanofibers. The in-depth surface chemistry analyses for zein $/ \beta$ CD nanofibers were performed by XPS in order to determine to what extent $\beta-C D$ molecules are present on the surface of the zein nanofibers. Table 2 shows elementary compositions based on wide energy survey spectra of the $\beta-C D$, zein nanofibers and zein $/ \beta$ $C D$ nanofibers. Oxygen content outer surface of the samples was increased with the increasing the amount of $\beta-C D$ (from $10 \%$ to
$50 \%, w / w)$ used in the electrospinning of nanofibers. High energy resolution $\mathrm{C} 1 \mathrm{~s}$ spectra were also recorded to get more detailed information about surface chemistry of the zein/ $\beta-C D$ nanofibers. The overlay of normalized $C 1 \mathrm{~s}$ spectra of the zein nanofibers, zein $/ \beta-C D$ nanofibers and $\beta-C D$ are given in Fig. $5 b$. There are three different components for all of the $C 1 \mathrm{~s}$ high-resolution spectra. The position of one is at around $284.5 \mathrm{eV}, \mathrm{C} 1$, is assigned to aliphatic carbons, C-C and/or C-H (Shi et al., 2009; Uyar, Havelund, Hacaloglu, et al., 2010, 2009; Uyar, Havelund, Nur, et al., 2010, 2009). It is a prominent peak for pure zein nanofibers. The component $\mathrm{C} 2$ at about $285.7 \mathrm{eV}$ is arisen from either $\mathrm{C}-\mathrm{O}-\mathrm{C}$ or $\mathrm{C}-\mathrm{OH}$; and $\mathrm{C} 3$ (correlated to $\mathrm{O}-\mathrm{C}-\mathrm{O}$ ) located at around 287.7 were found in both zein nanofibers and $\beta-C D$ (Shi et al., 2009; Uyar, Havelund, Hacaloglu, et al., 2010; Uyar, Havelund, Nur, et al., 2010, 2009). The peaks are more distinctive for $\beta-C D$, therefore the relative concentrations of $C 2$ and $C 3$ increased with increasing amount of the $\beta-C D$ used in the preparation of zein/ $\beta-C D$ nanofibers. It is found that the increase in oxygen content is due to the presence of $\mathrm{C}-\mathrm{O}-\mathrm{C} / \mathrm{C}-\mathrm{OH}$ and/or $\mathrm{O}-\mathrm{C}-\mathrm{O}$ on the surface of zein nanofibers. The presence of

Table 2

Atomic concentrations generated from XPS wide energy survey scans.

\begin{tabular}{|c|c|c|c|}
\hline Samples & $\mathrm{C}(\%)$ & $\mathrm{O}(\%)$ & $\mathrm{N}(\%)$ \\
\hline$\beta-C D$ & 36.61 & 63.39 & - \\
\hline zein50 & 78.19 & 13.04 & 8.77 \\
\hline zein $50 / \beta-C D 10$ & 77.06 & 15.14 & 7.8 \\
\hline zein50/ß-CD25 & 75.43 & 16.25 & 8.32 \\
\hline zein50/ $\beta$-CD50 & 72.62 & 18.64 & 8.74 \\
\hline
\end{tabular}


the $\beta-C D$ on the surface of the zein/ $\beta-C D$ nanofibers is confirmed with these results. On the other hand, the $\beta-C D$ concentration of the probed volume is calculated as approximately $4 \%, 7 \%$ and $13 \%$ for zein $/ \beta-C D 10$, zein $/ \beta-C D 25$ and zein $/ \beta-C D 50$, respectively from the elementary compositions in Table 2 . The surface content of $C D$ for all three zein $/ \beta-C D$ samples is lower than the $C D$ content of the solutions they were prepared from. This indicates that the some of the $\mathrm{CD}$ molecules located on the fiber surface whereas some $C D$ molecules are buried in the bulk of the fiber matrix. Zein is a useful food packaging material (Alkan et al., 2011; Shi et al., 2009), and CDs have inclusion complexation capability with variety of molecules including aromas, colors, antioxidants, antibacterials, odors, and other functional ingredients (Del Valle, 2004; Hedges, 1998; Szejtli, 1998), therefore, zein/CD nanofibers may have the potentials to be used as active food packaging (Lópezde-Dicastillo, Gallur, Catalá, Gavara, \& Hernandez-Muñoz, 2010; López-de-Dicastillo, Jordá-Beneyto, Catalá, Gavara, \& HernandezMuñoz, 2011) materials owing to surface associated CD molecules and their high surface areas.

\subsection{Thermal characterization of zein/CD nanofibers}

The thermal characteristics of the zein/ $\beta$-CD nanofibers were studied by DSC and TGA. Fig. 6a displays the DSC thermograms of zein nanofibers and zein/ $\beta$-CD nanofibers containing $10 \%, 25 \%$ and $50 \%(w / w) \beta-C D$. Zein nanofibers and zein $/ \beta-C D$ nanofibers have shown a broad endothermic peak having a peak maximum at around $100^{\circ} \mathrm{C}$ in the DSC thermogram indicating that the samples contain some amount of water. The glass transition temperature $\left(T_{\mathrm{g}}\right)$ of the samples was also detected from the DSC thermograms. The $T_{\mathrm{g}}$ of the pure zein nanofibers was observed at around $154{ }^{\circ} \mathrm{C}$ which is in close agreement with the $T_{g}$ value reported in the literature for zein (Torres-Giner, Gimenez, \& Lagaron, 2008; TorresGiner, Ocio, \& Lagaron, 2009). The $T_{\mathrm{g}}$ values for zein50/ $\beta-\mathrm{CD} 10$, zein $50 / \beta-C D 25$ and zein50/ $\beta$-CD50 nanofibers were observed at around $158^{\circ} \mathrm{C}, 165^{\circ} \mathrm{C}$ and $172{ }^{\circ} \mathrm{C}$, respectively. It was clear that the higher $T_{\mathrm{g}}$ values were observed as the weight loadings of $\beta$ CD were increased from $10 \%$ to $50 \%$. The addition of CD in the zein nanofibers caused an increase in the $T_{\mathrm{g}}$ values which is possibly due to the less chain mobility of zein in the presence of CD.

Fig. 6b shows the TGA thermograms of pure $\beta-C D$, zein nanofibers and zein $\beta-C D$ nanofibers. The TGA of pure $\beta-C D$ has an initial weight loss $(\sim 12 \%)$ below $100^{\circ} \mathrm{C}$ and major weight loss between 325 and $350^{\circ} \mathrm{C}$ owing to water loss and main degradation of $\beta-C D$, respectively (Anitha et al., 2012). Similar to zein nanofibers, water loss for zein/ $\beta-C D$ nanofibers were also observed but the water weight percentage was around $3-5 \%(w / w)$ indicating that less amount of water was present in the nanofibers. In addition, another minor weight loss regime between 125 and $200^{\circ} \mathrm{C}$ was observed for zein nanofibers and zein/ $\beta-C D$ nanofibers. This weight loss is possibly due to the presence of remaining solvent (DMF) in the nanofiber samples.

The major weight loss for the zein nanofibers was recorded at around $275-350^{\circ} \mathrm{C}$ which is consistent with the main degradation temperature reported for the electrospun zein nanofibers (TorresGiner \& Lagaron, 2010; Woods, Selling, \& Cooke, 2009). Since the degradation temperature for zein and $\beta-C D$ was overlapped, we observed a single but broader weight loss for zein $/ \beta-C D$ nanofibers. Moreover, we observed that the thermal degradation of zein/CD nanofibers was shifted slightly to higher temperature with increasing $\beta$-CD content. Hence, zein/ $\beta$-CD nanofibers have shown slightly higher degradation temperature compared to pure zein nanofibers indicating that the incorporation of the $\mathrm{CD}$ molecules in the zein fiber matrix resulted in higher thermal stability.

\section{Conclusion}

Zein/CD nanofibers were obtained from electrospinning of zein/CD solutions in DMF. Three types of CDs $(\alpha-C D, \beta-C D$ and $\gamma$-CD) using different weight loadings (10\%, 25\% and $50 \%, w / w)$ were incorporated in zein solutions having various concentrations (40\%, 50\% and 60\%, w/v), and these zein/CD solutions were successfully electrospun. We found that the addition of CD in the zein solutions caused an increase in solution viscosity and therefore resulted in improvement of the electrospinnability, and less beaded structures and/or bead-free zein/CD nanofibers were obtained at lower zein concentrations when compared to pristine zein solutions. Depending on the zein concentration, $C D$ weight percentage and $C D$ type, bead-free zein/CD nanofibers having fiber diameters in the range of $\sim 100-400 \mathrm{~nm}$ were obtained. The morphological, structural, surface and thermal characterizations of zein/CD nanofibers were studied by SEM, XRD, ATR-FTIR, XPS, DSC and TGA. SEM imaging revealed that the morphologies of the electrospun zein/CD nanofibers were significantly affected by the CD weight percentage and $C D$ type added in zein/CD solutions. XRD study suggested structural changes for zein chain packing where the spacing of the inter-helix packing of zein chains was disturbed with the addition of CDs, in addition, it was found that CDs were mostly distributed in the fiber matrix without forming crystalline aggregates when lower weight percentages of CDs were used (10\% and $25 \%$ of $\beta-C D$ and $\gamma-C D$ and $10 \%$ of $\alpha-C D$ ), however, incorporation of $50 \%$ $(w / w)$ of all three types of CDs and $25 \%$ of $\alpha-C D$ yielded crystalline aggregates in the zein fiber matrix. The thermal analyses carried out by DSC and TGA indicated the improvement of thermal properties for zein $/ \beta-C D$ nanofibers, that is, zein $/ \beta-C D$ nanofibers have shown higher glass transition temperature and higher degradation temperature with increasing $\beta-C D$ content when compared to pristine zein nanofibers. The surface analyses by ATR-FTIR and XPS showed that some $C D$ molecules were present on the surface of zein $/ \beta$ $C D$ nanofibers. These electrospun zein/CD nanofibers may have the potential to be used as active food packaging materials owing to very high surface area of zein nanofibers and surface associated CD molecules since CD molecules have inclusion complexation capability with various molecules and therefore functional additives such as antioxidants, flavors, aromas, antibacterial agents can be complexed with CDs or removal of unpleasant odors from the surroundings can be achieved by CDs.

\section{Acknowledgements}

State Planning Organization (DPT) of Turkey is acknowledged for the support of UNAM-Institute of Materials Science and Nanotechnology. Dr. Uyar acknowledges Marie Curie International Reintegration Grant (IRG) NANOWEB (PIRG06-GA-2009-256428) and The Scientific \& Technological Research Council of Turkey (TUBITAK) (project \#111M459) for funding. F. Kayaci thanks to TUBITAK-BIDEB for national PhD study scholarship.

\section{References}

Agarwal, S., Greiner, A., \& Wendorff, J. H. (2009). Electrospinning of manmade and biopolymer nanofibers-Progress in techniques, materials, and applications. Advanced Functional Materials, 19(18), 2863-2879.

Alkan, D., Aydemir, L. Y., Arcan, I., Yavuzdurmaz, H., Atabay, H. I., Ceylan, C., et al. (2011). Development of flexible antimicrobial packaging materials against Campylobacter jejuni by incorporation of gallic acid into zein based films. Journal of Agricultural and Food Chemistry, 59(20), 11003-11010.

Andrew, J., \& Clarke, D. (2008). Enhanced ferroelectric phase content of polyvinylidene difluoride fibers with the addition of magnetic nanoparticles. Langmuir, 24(16), 8435-8438.

Anitha, S., Brabu, B., Thiruvadigal, D. J., Gopalakrishnan, C., \& Natarajan, T. (2012) Optical, bactericidal and water repellent properties of electrospun nanocomposite membranes of cellulose acetate and $\mathrm{ZnO}$. Carbohydrate Polymers 87(2), 1065-1072. 
Bai, J., Yang, Q., Li, M., Wang, S., Zhang, C., \& Li, Y. (2008). Preparation of composite nanofibers containing gold nanoparticles by using poly ( $\mathrm{N}$-vinylpyrrolidone) and [beta]-cyclodextrin. Materials Chemistry and Physics, 111(2-3), 205-208.

Bhardwaj, N., \& Kundu, S. C. (2010). Electrospinning: A fascinating fiber fabrication technique. Biotechnology Advances, 28(3), 325-347.

Chae, H. H., Kim, B. H., Yang, K. S., \& Rhee, J. I. (2011). Synthesis and antibacterial performance of size-tunable silver nanoparticles with electrospun nanofiber composites. Synthetic Metals, 161, 2124-2128.

Chigome, S., Darko, G., \& Torto, N. (2011). Electrospun nanofibers as sorbent material for solid phase extraction. Analyst, 136(14), 2879-2889.

Cristian, C., Bridges, C., Ha, S. W., \& Tonelli, A. E. (2005). Conformational changes induced in Bombyx mori silk fibroin by cyclodextrin inclusion complexation. Macromolecules, 38(13), 5640-5646.

Del Valle, E. (2004). Cyclodextrins and their uses: A review. Process Biochemistry, 39(9), 1033-1046.

Dong, H., Wang, D., Sun, G., \& Hinestroza, J. P. (2008). Assembly of metal nanoparticles on electrospun nylon 6 nanofibers by control of interfacial hydrogen-bonding interactions. Chemistry of Materials, 20(21), 6627-6632.

Fernandez, A., Torres-Giner, S., \& Lagaron, J. M. (2009). Novel route to stabilization of bioactive antioxidants by encapsulation in electrospun fibers of zein prolamine. Food Hydrocolloids, 23(5), 1427-1432.

Harada, A., Okada, M., Li, J., \& Kamachi, M. (1995). Preparation and characterization of inclusion complexes of poly (propylene glycol) with cyclodextrins. Macromolecules, 28(24), 8406-8411.

Harata, K. (1998). Structural aspects of stereodifferentiation in the solid state. Chemical Reviews, 98(5), 1803-1828.

He, D., Hu, B., Yao, Q. F., Wang, K., \& Yu, S. H. (2009). Large-scale synthesis of flexible free-standing SERS substrates with high sensitivity: Electrospun PVA nanofibers embedded with controlled alignment of silver nanoparticles. ACS Nano, 3(12), 3993-4002.

Hedges, A. (1998). Industrial applications of cyclodextrins. Chemical Reviews, 98(5), 2035-2044.

Jiang, H., Zhao, P., \& Zhu, K. (2007). Fabrication and characterization of zein-based nanofibrous scaffolds by an electrospinning method. Macromolecular Bioscience, $7(4), 517-525$.

Jiang, Q., Reddy, N., \& Yang, Y. (2010). Cytocompatible cross-linking of electrospun zein fibers for the development of water-stable tissue engineering scaffolds. Acto Biomaterialia, 6(10), 4042-4051.

Jiang, Q., \& Yang, Y. (2011). Water-stable electrospun zein fibers for potential drug delivery. Journal of Biomaterials Science, Polymer Edition, 22(10), 1393-1408.

Kayaci, F., \& Uyar, T. (2012). Solid inclusion complexes of vanillin with cyclodextrins: Formation, characterization and their high temperature stability. Food Chemistry, 133(3), 641-649.

Li, L., \& Hsieh, Y. L. (2005). Ultra-fine polyelectrolyte fibers from electrospinning of poly (acrylic acid). Polymer, 46(14), 5133-5139.

Li, Y., Lim, L., \& Kakuda, Y. (2009). Electrospun zein fibers as carriers to stabilize (-)-epigallocatechin gallate. Journal of Food Science, 74(3), C233-C240.

López-de-Dicastillo, C., Gallur, M., Catalá, R., Gavara, R., \& Hernandez-Muñoz, P. (2010). Immobilization of [beta]-cyclodextrin in ethylene-vinyl alcohol copolymer for active food packaging applications. Journal of Membrane Science, 353(1-2), 184-191.

López-de-Dicastillo, C., Jordá-Beneyto, M., Catalá, R., Gavara, R., \& HernandezMuñoz, P. (2011). Development of active polyvinyl alcohol/ $\beta$-cyclodextrin composites to scavenge undesirable food components. Journal of Agricultural and Food Chemistry, 59(20), 11026-11033.

Lu, X., Wang, C., \& Wei, Y. (2009). One-dimensional composite nanomaterials: Synthesis by electrospinning and their applications. Small, 5(21), 2349-2370.

Miyoshi, T., Toyohara, K., \& Minematsu, H. (2005). Preparation of ultrafine fibrous zein membranes via electrospinning. Polymer International, 54(8), 1187-1190.

Paraman, I., Lamsal, B. P., \& Recovery. (2011). Characterization of $\alpha$-zein from corn fermentation coproducts. Journal of Agricultural and Food Chemistry, 59, 3071-3077.

Parris, N., Cooke, P. H., \& Hicks, K. B. (2005). Encapsulation of essential oils in zein nanospherical particles. Journal of Agricultural and Food Chemistry, 53(12), 4788-4792.

Patel, A. R., Heussen, P., Hazekamp, J., Drost, E., \& Velikov, K. P. (2012). Quercetin loaded biopolymeric colloidal particles prepared by simultaneous precipitation of quercetin with hydrophobic protein in aqueous medium. Food Chemistry, 133(2), 423-429.

Ramakrishna, S., Fujihara, K., Teo, W., Lim, T., \& Ma, Z. (2005). An introduction to electrospinning and nanofibres. World Scientific Publishing Co. Ltd.

Ramakrishna, S., Fujihara, K., Teo, W., Yong, T., Ma, Z., \& Ramaseshan, R (2006). Electrospun nanofibers: Solving global issues. Materials Today, 9(3), 40-50.

Roso, M., Sundarrajan, S., Pliszka, D., Ramakrishna, S., \& Modesti, M. (2008). Multifunctional membranes based on spinning technologies: The synergy of nanofibers and nanoparticles. Nanotechnology, 19, 285707.

Rusa, C. C., Bullions, T. A., Fox, J., Porbeni, F. E., Wang, X., \& Tonelli, A. E. (2002). Inclusion compound formation with a new columnar cyclodextrin host. Langmuir 18(25), 10016-10023.
Saenger, W., Jacob, J., Gessler, K., Steiner, T., Hoffmann, D., Sanbe, H., et al. (1998). Structures of the common cyclodextrins and their larger analogues beyond the doughnut. Chemical Reviews, 98(5), 1787-1802.

Sanchez-Garcia, M. D., Hilliou, L., \& Lagaron, J. M. (2010). Nanobiocomposites of carrageenan, zein, and mica of interest in food packaging and coating applications. Journal of Agricultural and Food Chemistry, 58(11), 6884-6894.

Selling, G. W., Biswas, A., Patel, A., Walls, D. J., Dunlap, C., \& Wei, Y. (2007). Impact of solvent on electrospinning of zein and analysis of resulting fibers. Macromolecular Chemistry and Physics, 208(9), 1002-1010.

Selling, G. W., \& Woods, K. K. (2008). Improved isolation of zein from corn gluten meal using acetic acid and isolate characterization as solvent. Cereal Chemistry, 85(2), 202-206.

Selling, G. W., Woods, K. K., Sessa, D., \& Biswas, A. (2008). Electrospun zein fibers using glutaraldehyde as the crosslinking reagent: Effect of time and temperature. Macromolecular Chemistry and Physics, 209(10), 1003-1011.

Shi, K., Kokini, J. L., \& Huang, Q. (2009). Engineering zein films with controlled surface morphology and hydrophilicity. Journal of Agricultural and Food Chemistry, 57(6), 2186-2192.

Szejtli,J. (1998). Introduction and general overview of cyclodextrin chemistry. Chemical Reviews, 98(5), 1743-1754.

Szejtli, J. (2003). Cyclodextrins in the textile industry. Starch - Staerke, 55(5), 191-196.

Teo, W. E., \& Ramakrishna, S. (2009). Electrospun nanofibers as a platform for multifunctional, hierarchically organized nanocomposite. Composites Science and Technology, 69(11), 1804-1817.

Thavasi, V., Singh, G., \& Ramakrishna, S. (2008). Electrospun nanofibers in energy and environmental applications. Energy Er Environmental Science, 1(2), 205-221.

Torres-Giner, S., \& Lagaron, J. M. (2010). Zein based ultrathin fibers containing ceramic nanofillers obtained by electrospinning. I. Morphology and thermal properties. Journal of Applied Polymer Science, 118(2), 778-789.

Torres-Giner, S., Gimenez, E., \& Lagaron, J. (2008). Characterization of the morphology and thermal properties of zein prolamine nanostructures obtained by electrospinning. Food Hydrocolloids, 22(4), 601-614.

Torres-Giner, S., Ocio, M. J., \& Lagaron, J. M. (2009). Novel antimicrobial ultrathin structures of zein/chitosan blends obtained by electrospinning. Carbohydrate Polymers, 77(2), 261-266.

Uyar, T., Balan, A., Toppare, L., \& Besenbacher, F. (2009). Electrospinning of cyclodextrin functionalized poly (methyl methacrylate) (PMMA) nanofibers. Polymer, 50(2), 475-480.

Uyar, T., \& Besenbacher, F. (2008). Electrospinning of uniform polystyrene fibers: The effect of solvent conductivity. Polymer, 49(24), 5336-5343.

Uyar, T., \& Besenbacher, F. (2009). Electrospinning of cyclodextrin functionalized polyethylene oxide (PEO) nanofibers. European Polymer Journal, 45(4), 1032-1037.

Uyar, T., Hacaloglu, J., \& Besenbacher, F. (2009). Electrospun polystyrene fibers containing high temperature stable volatile fragrance/flavor facilitated by cyclodextrin inclusion complexes. Reactive E Functional Polymers, 69(3), $145-150$.

Uyar, T., Hacaloglu, J., \& Besenbacher, F. (2011). Electrospun polyethylene oxide (PEO) nanofibers containing cyclodextrin inclusion complex. Journal of Nanoscience and Nanotechnology, 11(5), 3949-3958.

Uyar, T., Havelund, R., Hacaloglu, J., Besenbacher, F., \& Kingshott, P. (2010). Functional electrospun polystyrene nanofibers incorporating $\alpha-, \beta-$, and $\gamma-$ cyclodextrins: Comparison of molecular filter performance. ACS Nano, 4(9), 5121-5130.

Uyar, T., Havelund, R., Hacaloglu, J., Zhou, X., Besenbacher, F., \& Kingshott, P. (2009). The formation and characterization of cyclodextrin functionalized polystyrene nanofibers produced by electrospinning. Nanotechnology, 20, 125605.

Uyar, T., Havelund, R., Nur, Y., Balan, A., Hacaloglu, J., Toppare, L., et al. (2010). Cyclodextrin functionalized poly (methyl methacrylate) (PMMA) electrospun nanofibers for organic vapors waste treatment. Journal of Membrane Science, $365,409-417$.

Uyar, T., Havelund, R., Nur, Y., Hacaloglu, J., Besenbacher, F., \& Kingshott, P. (2009). Molecular filters based on cyclodextrin functionalized electrospun fibers. Journal of Membrane Science, 332(1-2), 129-137.

Uyar, T., Hunt, M. A., Gracz, H. S., \& Tonelli, A. E. (2006). Crystalline cyclodextrin inclusion compounds formed with aromatic guests: Guest-dependent stoichiometries and hydration-sensitive crystal structures. Crystal Growth E Design, 6(5), 1113-1119.

Uyar, T., Nur, Y., Hacaloglu, J., \& Besenbacher, F. (2009). Electrospinning of functional poly (methyl methacrylate) nanofibers containing cyclodextrin-menthol inclusion complexes. Nanotechnology, 20, 125703.

Woods, K. K., Selling, G. W., \& Cooke, P. H. (2009). Compatible blends of zein and polyvinylpyrrolidone. Journal of Polymers and the Environment, 17(2), 115-122.

Xie, J., Li, X., \& Xia, Y. (2008). Putting electrospun nanofibers to work for biomedical research. Macromolecular Rapid Communications, 29(22), 1775-1792.

Yao, C., Li, X. S., \& Song, T. Y. (2009). Preparation and Characterization of Zein and Zein/Poly-L-lactide Nanofiber Yarns. Journal of Applied Polymer Science, 114(4), 2079-2086.

Yao, C., Li, X., \& Song, T. (2007). Fabrication of zein/hyaluronic acid fibrous membranes by electrospinning. Journal of Biomaterials Science, Polymer Edition, 18(6), 731-742.

Yao, C., Li, X., Song, T., Li, Y., \& Pu, Y. (2009). Biodegradable nanofibrous membrane of zein/silk fibroin by electrospinning. Polymer International, 58(4), 396-402. 
Yoon, K., Hsiao, B. S., \& Chu, B. (2008). Functional nanofibers for environmental applications. Journal of Materials Chemistry, 18(44), 5326-5334.

Zhang, P., Shao, C., Zhang, Z., Zhang, M., Mu, J., Guo, Z., et al. (2011). In situ assembly of well-dispersed $\mathrm{Ag}$ nanoparticles (AgNPs) on electrospun carbon nanofibers (CNFs) for catalytic reduction of 4-nitrophenol. Nanoscale, 3, 3357-3363.
Zhang, W., Chen, M., \& Diao, G. (2011). Electrospinning [beta]-cyclodextrin/poly (vinyl alcohol) nanofibrous membrane for molecular capture. Carbohydrate Polymers, 86, 1410-1416.

Zhong, Q., Jin, M., Davidson, P. M., \& Zivanovic, S. (2009). Sustained release of lysozyme from zein microcapsules produced by a supercritical anti-solvent process. Food Chemistry, 115(2), 697-700. 